Pesq. Vet. Bras. 35(12):951-955, dezembro 2015 DOI: $10.1590 / \mathrm{S} 0100-736 X 2015001200003$

\title{
Detecção de Brucella abortus em linfonodos de búfalas (Bubalus bubalis) em diferentes fases da gestação ${ }^{1}$
}

INDEX TERMS: Brucellosis, buffaloes, Bubalus bubalis, Brucella abortus, lymph nodes.

RESUMO.- 0 objetivo do presente trabalho foi verificar a presença do DNA de Brucella abortus e caracterizar as lesões causadas por esse agente em linfonodos de búfalas. Foram utilizadas 19 búfalas em diversos estágios de gestação, sorologicamente positivas para brucelose, submetidas ao abate sanitário, das quais se coletou fragmentos de diversos linfonodos. A idade fetal foi determinada através de exames ultrassonográficos associados à mensuração dos fetos durante a necropsia. Amostras foram coletadas e sub-

\footnotetext{
${ }^{1}$ Recebido em 25 de maio de 2015.

Aceito para publicação em 16 de dezembro de 2015.

${ }^{2}$ Faculdade de Medicina Veterinária, Instituto de Medicina Veterinária, Campus de Castanhal, Universidade Federal do Pará (UFPA), Rodovia BR316 Km 61, Castanhal, PA 68741-740, Brasil. *Autor para correspondência: diomedes@ufpa.br

${ }^{3}$ Departamento de Epidemiologia e Saúde Pública, Instituto de Veterinária (IV), Universidade Federal Rural do Rio de Janeiro (UFRRJ), Seropédica, RJ 23890-000, Brasil. E-mails: marilene@ufrrj.br, danielubiali@ hotmail.com

${ }^{4}$ Laboratório Nacional Agropecuário de Minas Gerais (Lanagro-MG), Av. Rômulo Joviano s/n, Fazenda Modelo, Pedro Leopoldo, MG 33600-000, Brasil.

${ }^{5}$ Colégio Técnico, UFRRJ, Campus Seropédica, BR-465 Km 7, Seropédica, RJ 23890-000. E-mail: jenevaldo@hotmail.com
}

metidas à qPCR e histopatologia. A detecção de DNA de $B$. abortus nos linfonodos das búfalas avaliadas foi verificada a partir do quarto mês de gestação em sete búfalas e em uma búfala pós-parição. Os achados histológicos foram linfadenite aguda a crônica. A presença de DNA de B. abortus foi detectada em todos os grupos de linfonodos avaliados, sendo que os linfonodos mais acometidos foram os mamários.

TERMOS DE INDEXAÇÃO: Brucelose, búfalos, Bubalus bubalis, Brucella abortus, linfonodos.

\section{INTRODUÇÃO}

Entre outras enfermidades diagnosticadas no estado do Pará, a brucelose em bubalinos se destaca, pois acomete muitos rebanhos, tanto da Ilha de Marajó como do continente (Silva et al. 2014). A enfermidade é caracterizada por ser uma zoonose bacteriana, causada por Brucella abortus, com importância econômica devido a problemas reprodutivos (Corbel 1997), sendo o principal agente para bubalinos B. abortus biotipo1 (Fosgate et al. 2002, Megid et al. 2005). As vias de infecção por B. abortus podem ser alimentar, genital ou respiratória e as fontes principais são fetos abortados, restos placentários, exsudatos uterinos ou 
sêmen contaminado (Payne 1959, Schlafer \& Miller 2007). Após a infecção, as bactérias migram para os linfonodos regionais, e como são microorganismos intracelulares facultativos, proliferam dentro dos macrófagos (Ackermann et al. 1988).

Fosgate et al. (2002) isolaram B. abortus por meio de cultura, a partir de um linfonodo mamário, somente em uma, dentre 17 búfalas sorologicamente positivas, naturalmente infectadas (Fosgate et al. 2002). Um estudo de infecção experimental por B. abortus em bubalinos jovens, com 3 e 6 meses de idade, revelou soroconversão de $29 \%$ dos bubalinos quando desafiados com a cepa S1969D, na dose de $1,7 \times 10^{10} \mathrm{UFC}$, e isolou-se B. abortus por meio da bacteriologia somente em homogeneizado de linfonodos parotídeos e pré-escapulares; contudo as contagens de B. abortus por grama nos linfonodos foram baixas e variaram entre $1,0 \times 10^{2}$ a $6,0 \times 10^{2} \mathrm{UFC}$ (Adesiyun et al. 2010). Os achados anatomopatológicos em linfonodos de bubalinos infectados experimentalmente por B. abortus são focos inflamatórios com fibroplasia (Adesiyun et al. 2010).

0 diagnóstico utilizado para brucelose em bubalinos tem sido baseado nas pesquisas de anticorpos por métodos sorológicos (Mathias et al. 1998, Fosgate et al. 2002, Molnár et al. 2002, Nasir et al. 2004, Bastianetto et al. 2005, Chaves et al. 2012, Silva et al. 2014, Pereira et al. 2015). Para demonstrar a presença desta bacteria a reação em cadeira da polimerase em tempo real (qPCR) detecta o DNA de Brucella spp. em fluidos e tecidos (Sola et al. 2014). Essa ferramenta, de grande valia, vem se destacando no diagnóstico da brucelose por apresentar altos níveis de sensibilidade e especificidade (Hinić et al. 2009, Caitano et al. 2014).

Poucos trabalhos demonstraram a presença de B. abortus nos linfonodos na espécie bubalina. 0 objetivo do presente trabalho foi verificar a presença de B. abortus, nos linfonodos de búfalas em diversos estágios de gestação, assim como caracterizar as lesões anatomopatológicas causadas por esse agente.

\section{MATERIAL E MÉTODOS}

Animais. Das 20 búfalas utilizadas no estudo de Sousa et al. (2015), 19 foram selecionadas para este trabalho, as quais eram mestiças, em diferentes estágios de gestação, primíparas, com idades de 24 a 30 meses, sorologicamente positivas para brucelose e provenientes da Ilha de Marajó, estado do Pará.

Coleta das amostras. Para confirmação da enfermidade foram coletadas amostras de sangue por venopunção da jugular, em tubos de $10 \mathrm{~mL}$, à vácuo. 0 soro foi separado por meio de centrifugação a 3000rpm, por cinco minutos e foram armazenados a $-20^{\circ} \mathrm{C}$ até a realização dos testes sorológicos. Os soros foram analisados por meio do teste de triagem do Antígeno Acidificado Tamponado (AAT), e os testes confirmatórios por meio de Fixação do Complemento (FC) e Polarização Fluorescente (PF), conforme recomenda o Manual Técnico do Programa Nacional de Controle e Erradicação da Brucelose e Tuberculose Animal (Brasil 2006); todos os testes foram realizados no Instituto Biológico em São Paulo.

Os animais do presente estudo foram submetidos ao abate sanitário em matadouros frigoríficos localizados nos municípios de Castanhal e Belém, estado do Pará, sob inspeção estadual e federal, respectivamente, conforme a legislação vigente. 0 período gestacional foi determinado através de exame ultrassonográfico, realizados mensalmente, associados à mensuração do feto durante o abate, conforme recomendado por Barr et al. (1990).

Para a PCR foi realizada a coleta dos linfonodos parotídeo, pré-escapular, mediastínico, pré-crural e mamário das búfalas em diversos estágios de gestação. As amostras foram coletadas com a utilização de equipamentos de proteção individual (EPI), tubos e frascos esterilizados para coleta individual. As amostras foram congeladas e enviadas ao Laboratório de Biologia Molecular do Laboratório Nacional Agropecuário em Minas Gerais (LBM - Lanagro/MG) para realização da reação em cadeira da polimerase (qPCR).

Para os exames histopatológicos foram avaliados os linfonodos parotídeo, retrofaríngeo, submandibular, pré-escapular, pré-crural, mesentérico, ilíaco interno, íleofemural, mamário e uterino. Essas amostras foram fixadas em formol a 10\% e enviadas ao Setor de Anatomia Patológica, do Instituto de Veterinária da Universidade Federal Rural do Rio de Janeiro (UFRRJ), as quais foram submetidas ao processamento de rotina para histopatologia, cortadas a $5 \mu \mathrm{m}$ e coradas pela hematoxilina e eosina (HE).

Extração de DNA. Todas as amostras de tecidos foram submetidas à extração de DNA genômico com o kit comercial QIAamp Cador Pathogen mini kit (Qiagen ${ }^{\circledR}$ ), utilizando-se o protocolo recomendado conforme o fabricante. O DNA extraído foi analisado e quantificado em gel de agarose a 0,8\%, com marcador de peso molecular $1 \mathrm{~Kb}$, corado com blue green (LGCbio), visualizado em luz ultravioleta e fotodocumentado para verificação de sua qualidade.

PCR em Tempo Real (qPCR). 0 ensaio foi realizado utilizando-se os oligonucleotídeos Bru.is711.128.F (TGGTGCTGTCAATGAGGAC), Bru.is711.128.F (GACCTTCGGCAAATGGACAG), Bru. is711.128.S (5'.FAM-CGGCGTATCAGCCAGGGCAT-IowaBlack.3') para amplificação da sequência de inserção 711 do gênero Brucella. Após as extrações dos DNAs, as reações de amplificação foram realizadas em um volume final de $25 \mu \mathrm{L}$ contendo: $2,5 \mu \mathrm{L}$ de DNA genômico; $2,0 \mu \mathrm{L}$ de cada primer à $10 \mu \mathrm{M} ; 4,4 \mu \mathrm{L}$ de água Mili-Q ultrapura, $0,6 \mu \mathrm{L}$ de $\mathrm{MgCl}_{2}, 1,0 \mu \mathrm{L}$ de sonda e $12,5 \mu \mathrm{L}$ de Mix Quantitect (Qiagen, Alemanha) de acordo com o protocolo do fornecedor. As condições de termociclagem foram as seguintes: $50^{\circ} \mathrm{C}$ por 2 minutos, desnaturação a $95^{\circ} \mathrm{C}$ por 15 minutos, seguidos de 45 ciclos a $95^{\circ} \mathrm{C}$ por 15 segundos e $60^{\circ} \mathrm{C}$ por um minuto. Todas as amostras foram avaliadas em duplicata em termociclador LigthCycler $^{\circledR} 480$ II (Roche), com Software Release 1.5.0 SP4.

\section{RESULTADOS}

Foram analisadas 95 amostras de linfonodos, das quais em $11,57 \%$ (11/95) foram detectados DNA de Brucella abortus.

A presença de DNA de B. abortus foi detectada em $10,52 \%(2 / 19)$ dos linfonodos parotídeos, em 5,26\% (1/19) dos linfonodos pré-escapulares, em 5,26\% (1/19) dos linfonodos mediastínicos, em 10,52\% (2/19) dos linfonodos pré-crurais e em 26,31\% (5/19) dos linfonodos mamários (Quadro 1). A detecção de DNA de B. abortus nos linfonodos das búfalas avaliadas foi verificada a partir do quarto mês de gestação em sete búfalas e em uma búfala pós-parição.

\section{Achados anatomopatológicos}

Não foram observadas alterações macroscópicas. Os principais achados histológicos foram: linfonodos parotídeos: acentuada congestão, moderado edema subcapsular, leucocitoestase de neutrófilos, leve infiltração por neutrófilos e eosinófilos, pequenos focos com filamentos de fibrina 
Quadro 1. Detecção de DNA de Brucella abortus nos linfonodos e meses gestacionais correspondentes das búfalas (Bubalus bubalis) sorologicamente positivas

\begin{tabular}{ccc}
\hline $\begin{array}{c}\text { Identifi- } \\
\text { cação }\end{array}$ & $\begin{array}{c}\text { Idade } \\
\text { gestacional } \\
\text { (Meses) }\end{array}$ & $\begin{array}{c}\text { Parotídeo Pré-es- Medias- Pré-crural Mamário } \\
\text { capular tínico }\end{array}$ \\
\hline
\end{tabular}

Búfala1 2o

Búfala $2 \quad 2^{\circ}$

Búfala $3 \quad 2$ o

Búfala $4 \quad 2$ o

Búfala $5 \quad 3$

Búfala $6 \quad$ 3은

Búfala 7

Búfala 8

Búfala 9

Búfala 10

Búfala 11

Búfala 12

Búfala 13

Búfala 14

Búfala 15

Búfala 16

Búfala 17

Búfala 18

Búfala 19 Pós-parto

+ Positivo, - negativo.

e áreas de fibrose nos seios subcapsulares e paracorticais. Linfonodos retrofaríngeos: discreto infiltrado por neutrófilos e eosinófilos em meio a ninhos de células histiocitárias. Linfonodos submandibulares: acentuadas congestão e hemorragia, leve edema e pequenos focos com filamentos de fibrina e leve hiperplasia dos folículos linfoides. Linfonodos pré-escapulares: moderada congestão, leve a moderado edema, pequenos focos de infiltração por neutrófilos, raras figuras de cariorrexia, pequenos focos com filamentos de fibrina, rarefação linfoide (Fig.1 e 2), proliferação histiocitária moderada nos seios paracorticais, pequenos focos de infiltração por neutrófilos e leve a moderada hiperplasia linfoide com frequentes mitoses. Linfonodos pré-crurais: leve edema difuso, algumas figuras de cariorrexia, rarefação linfoide ou leve hiperplasia linfoide, frequentes mitoses em folículos linfoides, proliferação de células histiocitárias (Fig.3 e 4) no centro de folículos e na região medular e

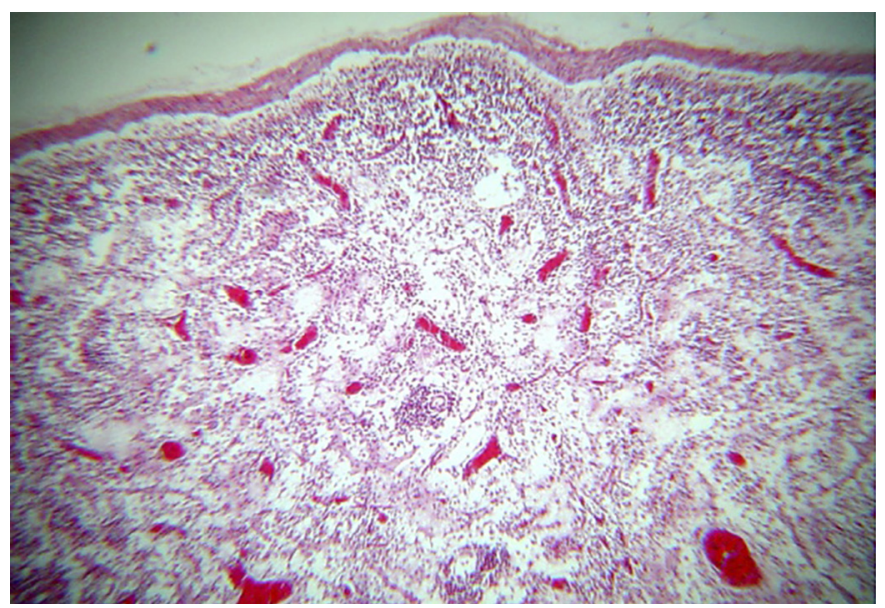

Fig.1. Linfonodo de búfala com brucelose. Rarefação linfoide, marcada congestão e edema. HE, obj.4x.

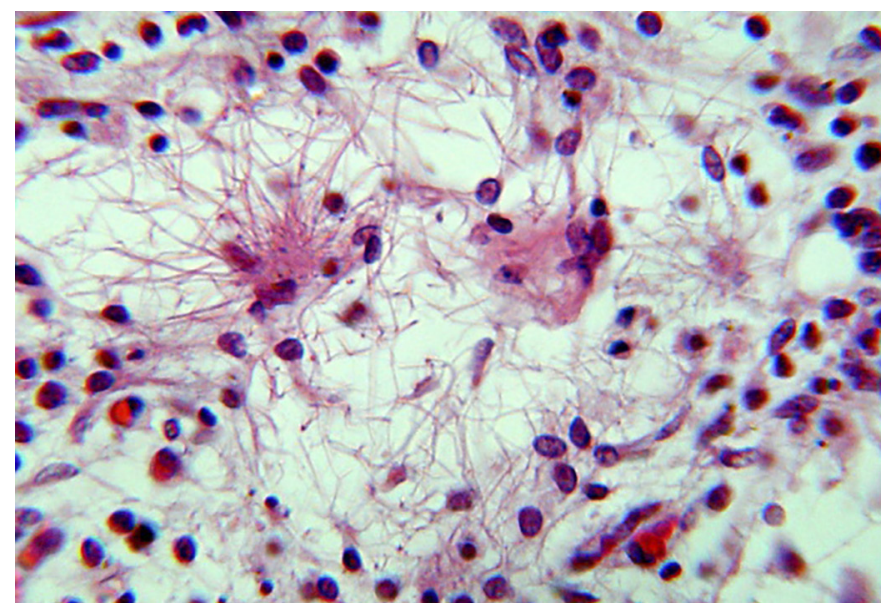

Fig.2. Linfonodo de búfala com brucelose. Edema e fibrina no seio medular. HE, obj.25x.

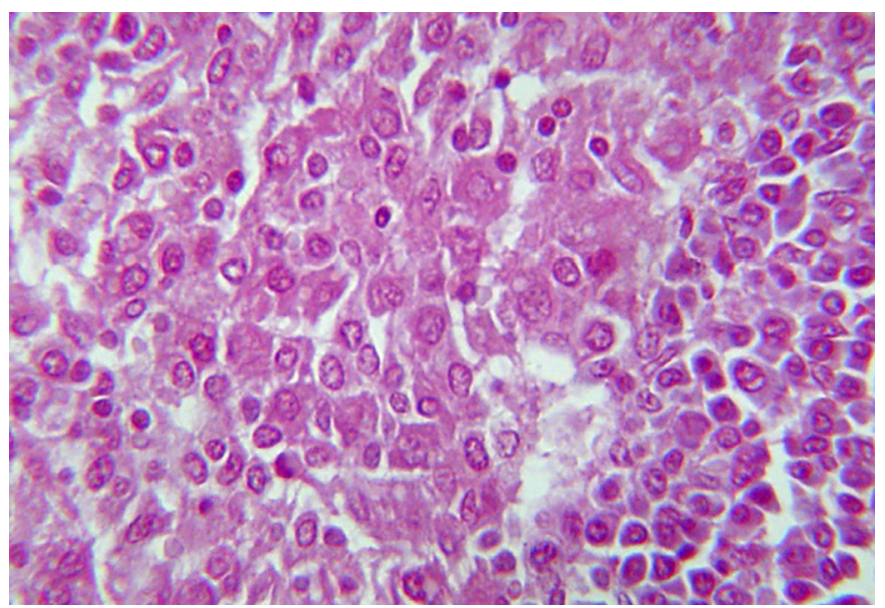

Fig.3. Linfonodo de búfala com brucelose. Proliferação histiocitária no seio paracortical. HE, obj.40x.

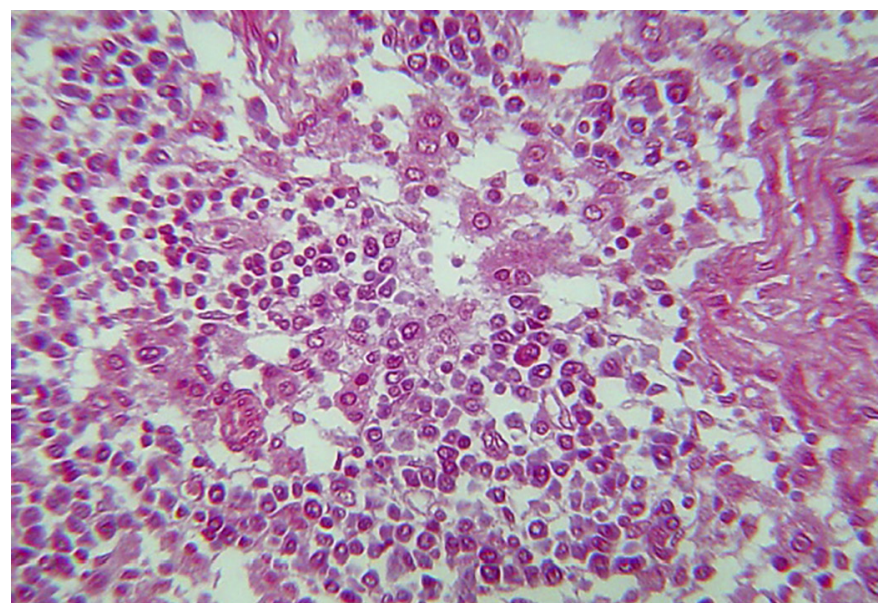

Fig.4. Linfonodo de búfala com brucelose. Edema e proliferação histiocitária no seio medular. HE, obj.16x.

leve a moderada infiltração por neutrófilos nos seios paracorticais. Linfonodos mamários: leve hiperplasia linfoide, infiltração por neutrófilos e eosinófilos nos seios paracorticais e medulares, moderada proliferação de células histiocitárias em folículos linfoides e nos seios medulares. Linfonodos ilíacos internos: proliferação de células histio- 
citárias nos seios subcapsulares e paracorticais, frequentes plasmócitos, raros neutrófilos subcapsulares, com edema e fibrina em organização e leve hiperplasia linfoide. Linfonodos íleofemurais: leve edema na região medular, focos com infiltração por neutrófilos, leve hiperplasia folicular e proliferação histiocitária paracortical. Linfonodos mesentéricos: rarefação de folículos linfoides, leve proliferação de células histiocitárias e leve edema nos seios medulares. Linfonodos uterinos: leve hiperplasia linfoide, moderada infiltração por neutrófilos e eosinófilos nos seios paracorticais e medulares e frequentes plasmócitos.

\section{DISCUSSÃO}

As alterações encontradas nos linfonodos das búfalas deste estudo são compatíveis com brucelose em ruminantes e complementam os dados encontrados no estudo prévio realizado por Souza et al. (2015). Verificou-se DNA de Brucella abortus nos linfonodos mamários, mediastínicos, parotídeos, pré-crurais e pré-escapulares. Paulin \& Ferreira Neto (2003) descreveram que B. abortus é frequentemente isolada de linfonodos mamários, seguidos dos retrofaríngeos, mandibulares, parotídeos, pré-escapulares e ilíacos.

A detecção de DNA de B. abortus nos linfonodos das búfalas avaliadas, verificada a partir do quarto mês de gestação no linfonodo pré-escapular, e no sétimo mês no linfonodo mediastínico, sugere a possibilidade de infecção inicial por via respiratória, concordando com Lira (2008), para posterior instalação no útero e regiões que drenam o local. A presença de B. abortus nos linfonodos parotídeos a partir do sexto mês de gestação também sugere a via oral como outra fonte de infecção, o que também foi relatado por Lira (2008).

A detecção de DNA de B. abortus ocorreu principalmente nos linfonodos mamários, e em menor intensidade nos linfonodos pré-crurais; isso provavelmente se deve ao fato de que esses linfonodos drenam a região da glândula mamária e útero, pois segundo Ko \& Splitter (2003), esses são locais de predileção das bactérias em animais no período gestacional devido à grande concentração de produtos da degradação do eritritol. Além disso, tem sido sugerido que os linfonodos que drenam as áreas de infecção ou de lesões têm maior chance de serem positivos para B. abortus (Forbes et al. 1989, Palmer et al. 1996). Xavier et al. (2009), verificaram que em vacas prenhes, experimentalmente infectadas por B. abortus, os principais locais onde isolaram a bactéria foram os linfonodos mamários e a glândula mamária. Os achados do presente trabalho são semelhantes aos encontrados por Adesiyun et al. (2010), que isolaram $B$. abortus a partir de homogeneizados de linfonodos parotídeos e pré-escapulares de búfalos com 3 a 6 meses de idade, locais próximos ao local de inoculação da bactéria, que foi por via intraconjuntival. Lira (2008) relata a maior frequência da presença de DNA de B. ovis nos linfonodos inguinais e parotídeos de ovinos inoculados experimentalmente, explicado pela proximidade com a via de inoculação da bactéria que foi por via intraprepucial e conjuntival respectivamente.

Os principais achados histológicos nos linfonodos do presente estudo foram em alguns linfonodos ora hiperplasia, ora rarefação linfoide, congestão, edema, filamentos de fibrina, bem como infiltrados de neutrófilos, eosinófilos e plasmócitos, infiltrados de células histiocitárias e áreas de fibrose. Segundo Schlafer \& Miller (2007) a infeccção por B. abortus pode ser debelada nos linfonodos regionais, mas após estabelecida a inflamação espera-se que haja disseminação do agente durante a fase inflamatória aguda. Pode ocorrer disseminação sistêmica do agente ou a infeccção pode se tornar crônica. Nos linfonodos desse estudo foram observadas linfadenite tanto aguda quanto crônica. Esses achados foram semelhantes aos encontrados por Adesiyun et al. (2010), que verificaram focos inflamatórios com fibroplasia; os autores compararam a infecção experimental por B. abortus em bovinos e bubalinos, e observaram que as lesões histológicas foram verificadas em maior intensidade nos bubalinos. Já os achados de Xavier et al. (2009) foram linfonodos ilíacos internos e mamários com graus variados de hiperplasia linfoide associada com infiltrados neutrofílicos e infiltrados histiocíticos na medula e paracórtex, em bovinos infectados experimentalmente por B. abortus. Nos linfonodos supramamários de bovinos com brucelose Godfroid et al. (2004) relatam hiperplasia linfoide, plasmocitose medular e histiocitose dos seios. Em ovinos, Lira (2008) relatou, em inoculação experimental com a cepa REO 198 de B. ovis, linfonodos parotídeos, pré-escapulares, faríngeos, mediastínicos, mesentéricos e inguinais com rarefação linfoide e edema na medular.

Embora tenha sido detectado DNA de B. abortus nos linfonodos de búfalas em vários meses de gestação, não foram observadas alterações macroscópicas nos linfonodos. Porém microscopicamente foram verificadas congestão, edema, fibrina, infiltração por neutrófilos, histiócitos e plasmócitos, o que que caracteriza uma linfadenite regional; segundo Schlafer \& Miller (2007) esses achados demonstram a passagem das brucelas pelos linfonodos regionais nas áreas da infecção.

A não detecção de DNA de B. abortus nos linfonodos em alguns dos animais do presente estudo pode ser explicada pelo fato de que após a bacteremia, as brucelas são fagocitadas pelos macrófagos e se multiplicam nos linfonodos regionais, depois invadem o lúmen uterino e as vilosidades coriônicas, onde há maior disponibilidade de substratos para sua multiplicação, como relatado por Ko \& Splitter (2003). Portanto, a não identificação do agente sustenta a relação de migração e passagens transitórias do agente pelos tecidos. Essa hipótese também foi levantada por Lira (2008) em ovinos e por Sola et al. (2014) em bovinos.

\section{CONCLUSÃO}

A presença de DNA de Brucella abortus foi detectada em todos os grupos de linfonodos avaliados a partir do quarto mês de gestação das búfalas, sendo que os linfonodos mais acometidos foram os mamários. Diagnosticou-se linfadenite aguda a crônica ao exame histológico.

\section{REFERÊNCIAS}

Ackermann M.R., Cheville N.F. \& Deyeoe B.L. 1988. Bovine ileal dome lymphoepithelial cell: endocytosis and transport of Brucella abortus strain 19. Vet. Pathol. 25:28-35.

Adesiyun A.A., Fosgate G.T., Persad A., Campbell M., Seebaransingh R. \& Stewart-Johnson A. 2010. Comparative study on responses of cattle and 
water buffalo (Bubalus bubalis) to experimental inoculation of Brucella abortus biovar 1 by the intraconjunctival route: a preliminary report. Trop. Anim. Health Prod. 42(8):1685-1694.

Barr B.C., Anderson M.L., Blanchard P.C., Daft B.M., Kinde H. \& Conrad P.A. 1990. Bovine fetal encephalitis and myocarditis associated with protozoal infections. Vet. Pathol. 27(5):354-361.

Bastianetto E., Amaral F.R., Carvalho L.B., Oliveira D.A.A. \& Leite R.C. 2005. Brucelose em rebanhos de búfalos criados na região do Alto São Francisco, Minas Gerais. Revta Bras. Reprod. Anim. 29(1):55-56.

Brasil. Ministério da Agricultura, Pecuária e Abastecimento. 2006. Programa nacional de controle e erradicação da brucelose e da tuberculose animal: manual técnico. Mapa, Brasília. 188p.

Caitano M.A.B., Soares C.O., Ramos C.A.N., Ferraz A.L.J., Sanches C.C. \& Rosinha G.M.S. 2014. Detecção de Brucella abortus em tecidos bovinos utilizando ensaios de PCR e qPCR. Pesq. Vet. Bras. 34(6):497-502.

Chaves N.P., Bezerra D.C., Santos L.S., Sá J.S., Santos H.P. \& Pereira H.M. 2012. Intercorrência entre leucose enzoótica e brucelose em búfalos (Bubalus bubalis) em sistema de produção extensivo. Pesq. Vet. Bras. 32(2):131-134.

Corbel M.J. 1997. Brucellosis: an overview. Emerg. Infect. Dis. 3:213-221.

Forbes L.B. \& Steele T.B. 1989. An outbreak of Brucella abortus biovar 2 in Canadian cattle. Can. Vet. J. 30:888-893.

Fosgate G.T., Diptee M.D., Ramnanan A. \& Adesiyun A.A. 2011. Brucellosis in domestic water buffalo (Bubalus bubalis) of Trinidad and Tobago with comparative epidemiology to cattle. Trop. Anim. Health Prod. 43:14791486.

Godfroid J., Bosman P.P., Herr S. \& Bishp G.C. 2004. Bovine brucellosis, p.1510-1527. In: Coetzer Jaw \& Tustin R.C. (Eds), Infectious Diseases of Livestock. Vol.3. 2nd ed. Oxford University Press, Cape Town. 2159p.

Hinić V., Brodard I., Thomann A., Holub M., Miserez R. \& Abri C. 2009. IS711-based real-time PCR assay as a tool for detection of Brucella spp. in wild boars and comparison with bacterial isolation and serology. BMC Vet. Res. 5:1-8.

Ko J. \& Splitter G.A. 2003. Molecular host-pathogen interaction in brucellosis: current understanding and future approaches to vaccine development for mice and humans. Clin. Microbiol. Rev. 6:65-78.

Lira N.S.C. 2008. Lesões anatomopatológicas e detecção da Brucella ovis cepa REO 198 em ovinos inoculados experimentalmente pelas vias intraprepucial e conjuntival simultaneamente. Tese de Doutorado, Unesp-Botucatu, SP.
Mathias L.A., Chaves L.F., Girio R.J.S. \& Del Fava C. 1998. Avaliação de um teste imunoenzimático competitivo no diagnóstico sorológico da brucelose em búfalos (Bubalus bubalis). Pesq. Vet. Bras. 18(3/4):111-114.

Megid J., Albert D., Fagliari J.J., Paes A.C., Listoni F.P., Pinto A.C., Ribeiro M.G., Thiébaud M., Ueno T. \& Garin-Bastiji B. 2005. Isolation of Brucella abortus from cattle and water buffalo in Brazil. Vet. Rec. 156(5):147-148.

Molnár L., Molnár E., Lima E.S.C. \& Dias H.L.T. 2002. Avaliação de seis testes sorológicos no diagnóstico da brucelose bubalina. Pesq. Vet. Bras. 22(2):41-44.

Nasir A.A., Parveen Z., Shah M.A. \& Rashid M. 2004. Seroprevalence of brucellosis in animals at government and private livestock farms in Punjab. Pak. Vet. J. 24(3):144-146.

Palmer M.V., Olsen S.C., Gilsdorf M.J., Philo L.M., Clarke P.R. \& Cheville N.F. 1996. Abortion and placentitis in pregnant bison (Bison bison) induced by the vaccine candidate, Brucella abortus strain RB51. Am. J. Vet. Res. 57:1604-1607.

Paulin L.M. \& Ferreira Neto J.S. 2003. 0 combate à brucelose bovina: situação brasileira. Funep, Jaboticabal. 154p.

Payne J.M. 1959. The pathogenesis of experimental brucellosis in the pregnant cow. J. Pathol. Bacteriol. 78:447-463.

Pereira A.P.M., Casseb A.R., Casseb L.M.N., Vale W.G. \& Pereira W.L.A. 2015. Humoral immune response of buffalo heifers (Bubalus bubalis) vaccinated with B19 strain of Brucella abortus. Archs Vet. Sci. 20(1):56-61.

Schlafer D.H. \& Miller R.B. 2007. Female genital system, p.429-564. In: Maxie M.G. (Ed.), Jubb, Kennedy and Palmer's Pathology of Domestic Animals. Vol.3. 5th ed. Saunders Elsevier, Toronto. 737p.

Silva J.B., Fonseca A.H. \& Barbosa J.D. 2014. Serological survey of Mycobacterium bovis, Brucella abortus and Borrelia burgdorferi in water buffaloes in the northern region of Brazil. Revta Salud Anim. 36(1):35-39.

Sola M.C., Veiga Jardim E.A.G., Freitas M.R. \& Mesquita A.J. 2014. Real-time PCR detection of Brucella spp. DNA in lesions and viscera of bovine carcasses. J. Microbiol. Methods 104:87-91.

Sousa M.G.S., Salvarani F.M., Bomjardim H.A., Fonseca Jr A.A., Preis I.S., Brito M.F., Leite R.C. \& Barbosa J.D. 2015. Infecção transplacentária e intrauterina por Brucella abortus em búfalos (Bubalus bubalis). Pesq. Vet. Bras. 35(11):882-888.

Xavier M.N., Paixão T.A., Poester F.P., Lage A.P. \& Santos R.L. 2009. Pathology, immunohistochemistry and bacteriology of tissues and milk of cows and fetuses experimentally infected with Brucella abortus. J. Comp. Pathol. 140(2/3):149-157. 